\title{
Carcinoma vesical de células pequeñas en un varón joven. Presentación de un caso y revisión de la literatura
}

\author{
M. Ramírez Backhaus, J.A. Queipo Zaragoza, J.L. Palmero Martí, J.M. Alapont Alacreu, \\ F.J. Vera Sempere*, J.F. Jiménez Cruz
}

Servicios de Urología y Anatomía Patológica*. Hospital Universitario La Fe.Valencia.

Actas Urol Espo 2006; 30 (3): 326-330

\begin{abstract}
RESUMEN
CARCINOMA VESICAL DE CÉLULAS PEQUEÑAS EN UN VARÓN JOVEN. PRESENTACIÓN DE UN CASO Y REVISIÓN DE LA LITERATURA

El carcinoma vesical de células pequeñas u "oat cell" de vejiga es una entidad infrecuente que se caracteriza por un comportamiento clínico agresivo y alta incidencia de metástasis a distancia. Presentamos un caso clínico de carcinoma vesical de células pequeñas en un varón joven que se trató con cirugía radical y radioterapia pélvica, seguido de un esquema de quimioterapia CDDP. El paciente falleció 6 meses después de la intervención como consecuencia de progresión de la enfermedad. Realizamos una revisión y actualización de la literatura al respecto.
\end{abstract}

Palabras clave: Carcinoma de células pequeñas. Vejiga. Manejo terapéutico.

\section{ABSTRACT}

SMALL CELL CARCINOMA OF THE URINARY BLADDER IN A YOUNG MAN. A CASE REPORT AND LITERATURE REVIEW

Small cell carcinoma of the bladder is a rare entity characterized by an aggressive clinical behaviour with a high incidence of systemic metastases. We report a case of small cell carcinoma of the bladder in a young man. The primary local tumour was treated by radical surgery, pelvic radiation therapy and polychemotherapy according CDDP protocol. The patient died six months after surgery because disease progression. We also review and update the literature concerning this infrequently tumour.

Keywords: Small cell carcinoma. Bladder. Therapeutic management.

$\mathrm{E}_{\mathrm{c}}^{1}$ carcinoma de células pequeñas, también conocido como carcinoma anaplásico neuroendocrino, carcinoma indiferenciado o carcinoma de tipo "oat cell" fue descrito inicialmente a principios del siglo pasado por Barnard, quien aportó la primera referencia bibliográfica al respecto sobre su localización a nivel pulmonar. Fuera de este órgano, puede localizarse en piel, cavidad nasal y senos paranasales, laringe-tráquea, timo, glándulas parótidas y salivares, tracto gastrointestinal y genitourinario. A nivel del tracto urinario ha sido descrito en riñón, uréter y próstata, siendo Cramer et al. ${ }^{1}$, los primeros autores en describir su localización vesical en una publicación que data del año 1981. Desde entonces hay alrededor de 200 casos publicados de este raro tumor. Sólo 11 revisiones cuentan con más de diez casos. La mayor de ellas la realizada por Nicholas Choong et al. de la Clínica Mayo ${ }^{2}$.

La vejiga y la próstata son las localizaciones más frecuentes en el tracto genitourinario ${ }^{3,4}$, siendo un tumor con un alto potencial de malignidad por su capacidad de diseminación a distancia. Presentamos un nuevo caso de carcinoma vesical de células pequeñas en un varón joven y realizamos una revisión literaria sobre esta entidad. 


\section{CASO CLÍNICO}

Paciente varón de 35 años sin antecedentes patológicos de interés, salvo hábito tabáquico importante (20-30 cigarrillos/día desde hacía mas de 10 años). Acudió al urólogo remitido por su médico de cabecera tras padecer un episodio de hematuria franca autolimitada. Posteriormente el paciente presentó otros episodios de emisión de pequeños coágulos junto a síndrome miccional irritativo intenso con urinocultivos repetidamente negativos. Inicialmente se practicó ecografía y urografía intravenosa, que evidenciaban una tumoración a nivel del trígono vesical, de $3 \mathrm{~cm}$ de diámetro, con leve ectasia ureteral izquierda. La función renal era normal (Creatinina: 1,3 $\mathrm{mg} / \mathrm{dL}$, Urea plasmática: $42 \mathrm{mg} / \mathrm{dL}$ ). Al tacto rectal se palpaba cierto aumento de consistencia prostática y del suelo vesical.

Ante el diagnóstico de tumor vesical primario se planteó al paciente la necesidad de realizar una resección transuretral. La cistoscopia intraoperatoria confirmaba la presencia de una neoplasia vesical sésil, de $2-3 \mathrm{~cm}$, con superficie bullosa y ulcerada que se situaba sobre el área trigonal. El resultado anatomopatológico informó de la presencia de una neoplasia constituida por células indiferenciadas de pequeño tamaño, distribuidas en "fila india", con algún foco aislado de carcinoma transicional, PSA (-) sin poder determinar el origen preciso del tumor. La infiltración afectaba a submucosa y muscular y la base de resección era positiva para tumor.

En espera de los resultados de los anatomopatológicos complementarios y los estudios de extensión en previsión de una posible cistectomía, 36 días después de la resección, el paciente ingresó por un síndrome constitucional severo, con perdida de peso de 10-12 kg, dolor en ambas fosas renales con hidronefrosis bilateral grado II/IV por atrapamiento ureteral e insuficiencia renal obstructiva (Creatinina $6,2 \mathrm{mg} / \mathrm{dL}$, Urea: $\left.176 \mathrm{mg} / \mathrm{dL}, \mathrm{K}^{+}: 5,6 \mathrm{mEq} / \mathrm{L}\right)$. Se practicó derivación urinaria urgente tipo nefrostomía percutánea, con un rápido restablecimiento de la función renal, iniciando durante el ingreso un nuevo episodio de hematuria macroscópica. Se realizó una cistoscopia que objetivó una gran tumoración sésil en la base vesical con infiltración de ambos meatos ureterales. Al tacto bimanual se palpaba una induración del suelo vesical de carácter irregular que parecía infiltrar próstata. Se solicitó un estudio de extensión mediante $\mathrm{Rx}$ simple de tórax, TAC abdomino-pélvico y rastreo oseo. En este momento no se objetivó enfermedad metastásica a distancia, objetivándose únicamente engrosamiento del suelo vesical, con ectasia urétero-pielo-calicial bilateral y ausencia de adenopatías (Fig. 1).

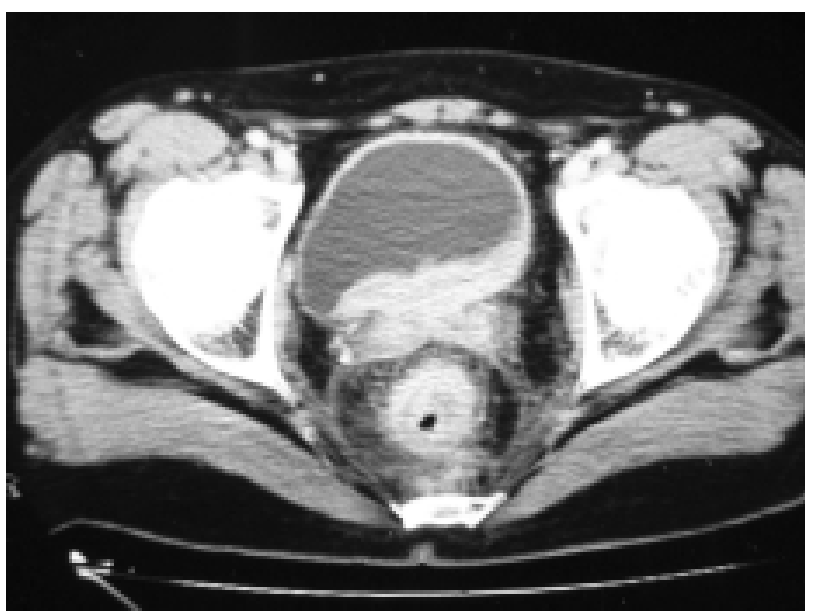

FIGURA 1: corte transversal del TAC preoperatorio donde se objetiva engrosamiento de la cara posterior de la pared vesical e infiltra grasa perivesical.

Ante estos hallazgos se realizó una cistoprostatectomía radical con reservorio continente tipo Indiana. Durante la intervención la liberación del suelo vesical resultó dificultosa dada la infiltración del mismo por el tumor. El resultado anatomopatológico (Fig. 2) confirmó la presencia de un carcinoma indiferenciado de células pequeñas, con tinciones inmunohistoquímicas: citoqueratina (+), enolasa neuronal específica (NSE) y Cromogranina (-), junto a pequeños focos de carcinoma transicional. El tumor afectaba todo el espesor de la pared vesical, grasa perivesical y periureteral derecha, pared rectal, próstata, vesículas seminales y 2 de los 8 ganglios de la iliaca común izquierda (Estadio:T4N2MO). El postoperatorio del paciente cursó sin dificultades y fue dado de alta a la semana de la intervención.

Ante el elevado riesgo de recidiva de la enfermedad, dada la afectación de bordes quirúrgicos y presencia de adenopatías, el comité de tumores de nuestro centro decidió realizar Quimio-Radioterapia adyuvante. Se instauró el esquema de 


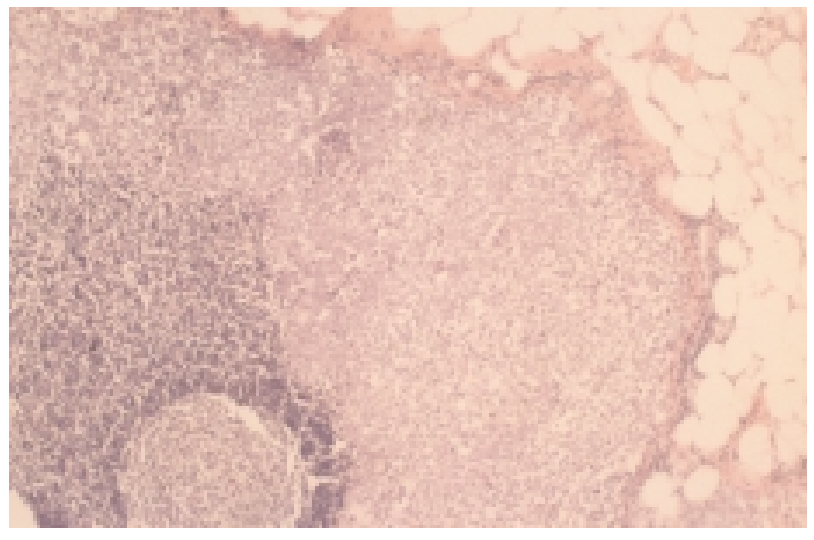

FIGURA 2: Imagen a microscopía óptica de hematoxilinaeosina de fragmento de RTU del tumor de células pequeñas de vejiga.

quimioterapia CDDP con radioterapia concomitante sobre pelvis con dosis de 50 Gy, a un ritmo de 180 cGy por sesión, 5 veces por semana, y posterior sobreimpresión con otros 14,4 Gy. La tolerancia a este régimen de tratamiento por parte del paciente fue óptima.

Tres meses después de la intervención y durante la administración de la QT/RT, acudió a la consulta aquejando molestias en hemiabdomen derecho que irradiaba a espalda sin otra clínica asociada. En la TAC abdomino-pélvica de control, se apreció un reservorio con buena capacidad, pequeña dilatación de la pelvis renal derecha, sin evidenciar colecciones ni signos de recidiva tumoral.

Otros tres meses después, el paciente presentó epigastralgia con irradiación hacia ambos hipocondrios, sensación de distensión postprandial inmediata y pirosis. A la exploración física se apreciaba una masa a nivel de hipocondrio-vacío derecho, no consiguiéndose apreciar por ecografía una posible recidiva tumoral a dicho nivel. Se solicitó una gastroscopia que mostró un estómago de retención con una estenosis píloro-duodenal de carácter extrínseco, planteándose la posibilidad de una infiltración metastásica del tumor versus una posible estenosis secundaria a la radioterapia. Ante estos hallazgos se decidió intervención quirúrgica, evidenciando en el transcurso de la misma presencia de recidiva tumoral en flanco derecho, invasión del duodeno por el tumor e implantes neoplásicos múltiples en epiplon, peritoneo y demás serosas, por lo que se practicó gastroyeyunostomía paliativa. Tras el postoperatorio, el enfermo fue remitido a su domicilio para cuidados paliativos, falleciendo al mes del alta ( 7 meses tras la cistectomía y 9 tras el diagnóstico).

\section{DISCUSIÓN}

El carcinoma vesical de células pequeñas es un tumor muy infrecuente $(0,5-1 \%$ de todos los tumores vesicales malignos $)^{3-7}$, que a diferencia del transicional (incluido el de alto grado y localmente avanzado) tiene un comportamiento extraordinariamente agresivo y con un pronóstico nefasto.

La distribución por edad y sexo presenta pocas diferencias respecto de los carcinomas transicionales apareciendo generalmente entre los 60-80 años, con una media de 65 y una relación varón/mujer de $3: 1^{2,4}$. Trias y Algaba ${ }^{6}$ y Seved et al. ${ }^{8}$ aumentan esta relación a 5:1. A pesar de ello y como en nuestro caso, también se ha descrito en pacientes jóvenes (menores de 40 años), siendo a estas edades muy infrecuente ${ }^{9}$.

El origen histológico de este tipo de tumor es controvertido. Algunos autores sostienen la teoría de un origen neuroendocrino (células tipo Kultschitzky), tal y como sucede en el tubo digestivo $^{5-7}$. Otros apuestan por una metaplasia de otros tumores de alto grado (con esta teoría se explicaría el que en muchos casos, estos tumores se hallan acompañados de otros patrones histológicos). Sin embargo, la mayoría de los autores abogan por el origen a partir de una células madre pluripotenciales (stem cell) ${ }^{4,7}$, cuya diferenciación daría lugar a células transicionales, escamosas, fusiformes y glandulares, componentes que focalmente acompañan habitualmente a este tipo de tumor en proporciones variables y que también podemos observar en el caso del carcinoma de células pequeñas que afecta al pulmón. Además, esta opción también justificaría la heterogeneidad de los hallazgos inmunohistoquímicos de los tumores de esta estirpe descritos en la literatura.

El 23-75\% de casos de carcinoma vesical de células pequeñas asocian otras variedades de tumor ${ }^{4,10}$. En el caso que presentamos, la anatomía patológica evidenció la presencia de focos aislados de carcinoma transicional. En otras series constan tumores con tres estirpes celula- 
res, carcinoma transicional y carcinoma escamoso o carcinoma transicional y adenocarcinoma de vejiga asociado al de células pequeñas ${ }^{2}$.

La microscocopía óptica este tumor se caracteriza por presentar células de pequeño tamaño y núcleo hipercromático con citoplasma escaso, presentando un alto índice mitótico y necrosis tumoral. La disposición celular suele ser en forma de nidos o hileras celulares ${ }^{4}$. Las tinciones inmunohistoquímicas muestran con frecuencia un perfil neuroendocrino con positividad para enolasa neuronal específica (la más frecuente) u otras como sinaptofisina, cromogranina A, Leu-7, serotonina y proteina S-100 etc..., si bien en otros casos no se expresan estos marcadores lo cual no influye en su agresivo comportamiento ${ }^{3-5}$. Los casos en que no hay dicha tinción, sugiere que el origen es una stem cell, más que una célula neuroendocrina especifica. Por ello también es posible que las técnicas inmunohistoquímicas frente a marcadores de células epiteliales (antígeno epitelial de membrana "EMA", citoqueratinas) resulten positivas, como en el caso que nos ocupa. De otra parte también es posible encontrar la presencia intracitoplasmática de gránulos neurosecretores, responsables de síndromes paraneopásicos, del tipo hipercalcemia, síndrome de Cushing o neuropatías sensoriales ${ }^{11}$ que en raras ocasiones acompañan a este tipo de tumor.

También hay descritas anomalías genéticas relacionadas con el carcinoma vesical de células pequeñas como delecciones en el brazo corto de los cromosomas 10, 4, 5, y 13 así como ganancia de DNA en los cromosomas 8q, 5p, 6p y 20q. Algunas de ellas coinciden con anomalías también descritas en el carcinoma de células transicionales ${ }^{12}$.

En los casi 200 casos publicados hasta el momento en la literatura el 94\% tienen invasión muscular, el $67 \%$ metástasis. Por orden de frecuencia: ganglios linfáticos, hígado, huesos, pulmón y sistema nervioso central ${ }^{11,13}$. En la serie de Choong et al. ${ }^{2}$ de la Clínica Mayo el 43,2\% de los pacientes presentan un estadio IV, es decir, T4a-bNOMO o cualquier $\mathrm{T}$ con ganglios afectos o con metástasis a distancia.

La mayoría de los tumores presentan micrometástasis al diagnóstico por lo que un abordaje quirúrgico es insuficiente y serán necesarios tra- tamientos adyuvantes basados en las mismas estrategias utilizadas para el carcinoma de células pequeñas pulmonar. Grignon et al. ${ }^{9}$ en su serie de 22 casos optan por un abordaje quirúrgico radical y quimioterapia adyuvante que varía en función de la histología tumoral, pautando: metotrexate, vinblastina, doxorrubicina y cisplatino si el tumor era de estirpe mixta; doxorrubicina, cisplatino y etopóxido si el tumor era únicamente de células pequeñas. Bex et al. ${ }^{14}$ así como Lohrisch et al. ${ }^{15}$ presentaron estudios posteriores con protocolos de quimioradioterapia y cirugía conservadora prolongando la supervivencia en pacientes con estadios precoces. Siefker-Radtke et al. ${ }^{16}$ demostraron que la quimioterapia neoadyuvante mejoraba la supervivencia en su serie de pacientes. Choong ${ }^{2}$, analizando su serie en función del estadio apuesta por la cistectomía radical excepto en los casos de M1 en los que la quimioterapia debería de ser el tratamiento de elección. Los regimenes basados en cisplatino no están justificados el estadio II y si en los estadios III y IV.

La mejor supervivencia global la aporta la revisión de Choong et cols. ${ }^{2}$ y es de 1,7 años, tres veces mayor que la aportada por la mayoría de series que oscilan entre 4 y 12 meses $^{11,13,15}$.

Dada la escasez de casos es imposible la estandarización del tratamiento, de hecho Sved et al. ${ }^{8}$ así como Bex et al. ${ }^{14}$ en sus respectivas revisiones concluyen que el pronóstico dependerá de la respuesta o sensibilidad del tumor a la quimioterapia dejando en un segundo plano al tratamiento quirúrgico. Por contra Choong et al. ${ }^{2}$ de la Clínica Mayo insisten en el papel primordial de la cirugía radical.

\section{CONCLUSIONES}

El carcinoma microcítico de vejiga (oat-cell vesical) que se diferencia del transicional de alto grado y del linfoma por sus características histológicas e inmunohistoquímicas, tiene un pronóstico sombrío sobre todo en los estadios avanzados como en el caso que presentamos.

No existe un tratamiento estandarizado debido a que su baja frecuencia impide que las series sean amplias, coincidiendo la mayoría de autores en la necesidad de cirugía radical y tratamientos adyuvantes (quimioterapia-radioterapia). 
El pronóstico de esta enfermedad es sombrío debido a su diagnóstico en estadios avanzados (principal factor pronóstico).

A nuestro entender la cirugía ha de ser precoz y radical ya que en las series más amplias que apuestan por tratamientos conservadores (cistectomía parcial o RTU) la necesidad de cistectomías de rescate resulta considerable.

\section{REFERENCIAS}

1. Cramer Sf, Aikawa M, Cebelin M. Neurosrcretory granules in small invasive carcinoma o the urinary bladder. Cancer. 1981;47:724-730.

2. Choong Nw, Quevedo Jf, Kaur JD. Small cell carcinoma of the urinary bladder. The Mayo Clinic experience. Cancer. 2005; 15:103(6): 1172-1178.

3. López JI, Angulo JC, Flores N, Toledo JD. Small cell carcinoma of the urinary bladder. A clinicopathological study of six cases. Br J Urol. 1994;73:43-49.

4. Fernández A, Peinado F, Gómez F, Arellano R, Morato P, Mínguez R et al. Aportación de un nuevo caso de carcinoma de células pequeñas de localización vesical y revisión de la literatura. Actas Urol Esp. 1999;23:876-879.

5. Muñoz D, García Miralles R, Amengual I, Benejam JM. Carcinoma vesical de células pequeñas. Aportación de un caso y revisión de la literatura. Actas Urol Esp. 2002;26; 811-815.

6. Trias I, Algaba F, Condom M, Español I, Segui J, Orsola I et al. Small cell carcinoma of the urinary bladder. Eur Urol. 2001; 39:85-90.

7. Ripa L, Delpon E, Fernández J, Cordoba A, Monzon FJ, Ruiz de Azua Y. Carcinoma de células pequeñas de vejiga. Aportación de un nuevo caso. Actas Urol Esp. 1997;21:495500.

8. Sved P, Gomez P, Manoharan M, Civantos F, Soloway M. Small cell carcinoma of the bladder. Br J Urol. 2004;94:12 17.
9. Golomb J, Lewin KJ, De Kernion JB, Raz S. Primary small cell carcinoma of the augmented urinary bladder. $\mathrm{Br} \mathrm{J}$ Urol. 1992;70:572-573.

10. Grignon DJ, Ayala AG, Shum DT, Ordoñez NG, Logothetis S, Johnson DE et al. Small cell carcinoma of the urinary bladder: clinicopathologic analysis of 22 cases. Cancer. 1992;69:27-536.

11. Abbas F, Civantos F, Benedetto P, Soloway MS. Small cell carcinoma of the bladder and prostate. Urology 1995;46: 617-630.

12. Terracciano L, Richter J, Tornillo L, Beffa L, Diener PA, Maurer R et al. Chromosomal imbalances in small cell carcinomas of the urinary bladder. J Path 1999;189:230-235.

13. Holmang S, Borghede G, Johansson SL. Primary small cell carcinoma of the bladder: a report of 25 cases. J Urol 1995; 153:1820-1822.

14. Bex A, Nieuwenhuijzen, Kerst M, Pos F, Van Boven H, Meinhardt W, et al. Small cell carcinoma of bladder: A single-centre prospective study of 25 cases treated in analogy to small cell lung cancer. J Urol 2005;65:295-299.

15. Lohrisch C, Murray N, Pickles T, Sullivan L. Small cell carcinoma of the bladder: long term outcome with integrated chemoradiation. Cancer. 1999; 86:2346-2352.

16. Siefker-Radtke AO, Dinney CP, Abrahams NA, Moran C, Shen Y, Pisters LL, et al. Evidence supporting preoperative chemotherapy for small cell carcinoma of the bladder: a retrospective review of the M. D. Anderson cancer experience. J Urol. 2004;172:481-484.

Dr. M. Ramírez Backhaus

Servicio de Urología (Secretaría)

Hospital Univ. La Fe

Avda. Campanar, 21

46009 Valencia

E-mail: ramirezbackhaus@yahoo.es

(Trabajo recibido el 23 de noviembre 2005) 